\title{
RESUMEPEMBUATAN PROGRAM APLIKASI BORLAND \\ DELPHI 7.0 BERBASIS PAPERPLAIN
}

NI WAYAN DAMAYANTI

175100013

Univeritas Mitra Indonesia,Sistem Informasi

wayandamayanti.student@umitra.ac.id

\section{Abstrak}

Abstrak merupakaan isi tulisan, abstrak sendiri berfunggsi untuk menjelaskan sebuah cara singkat kepada pembaca sedangkan abstrak ini ada intruksi penjelasan tentang aplikasi yang saya buat tidak mengacuh kepada objek.

\section{A. CAPTURE PROGRAM}

\section{PORTAL}

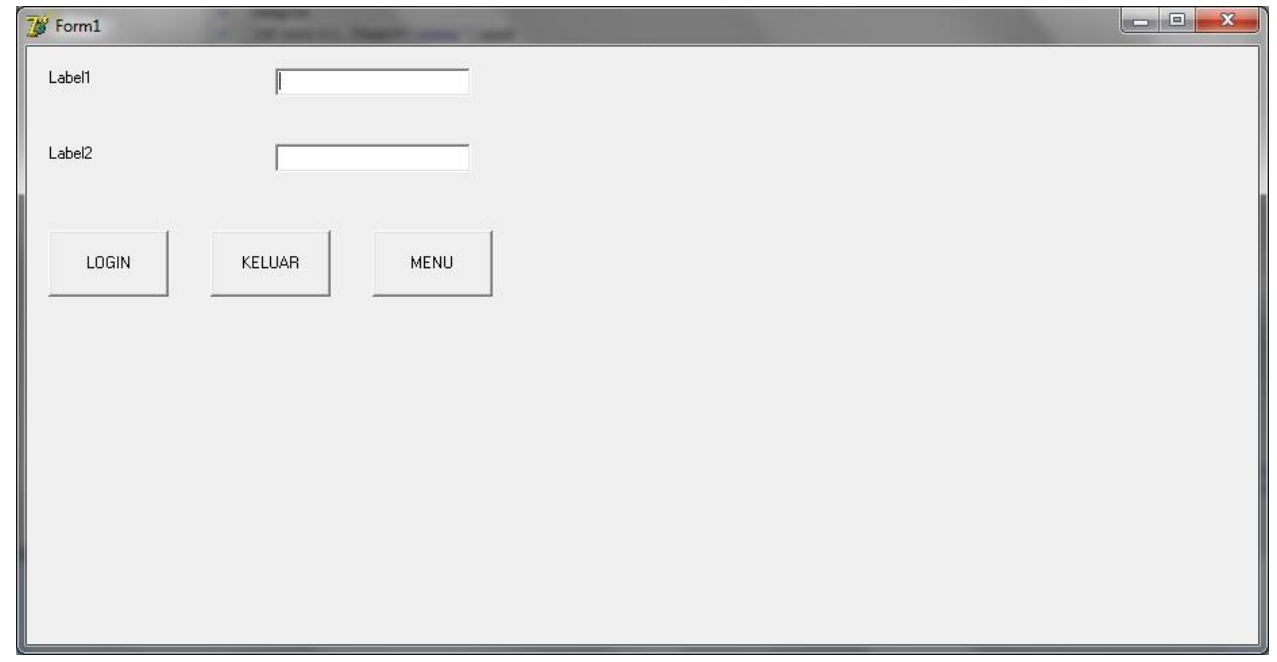

KALKULATOR

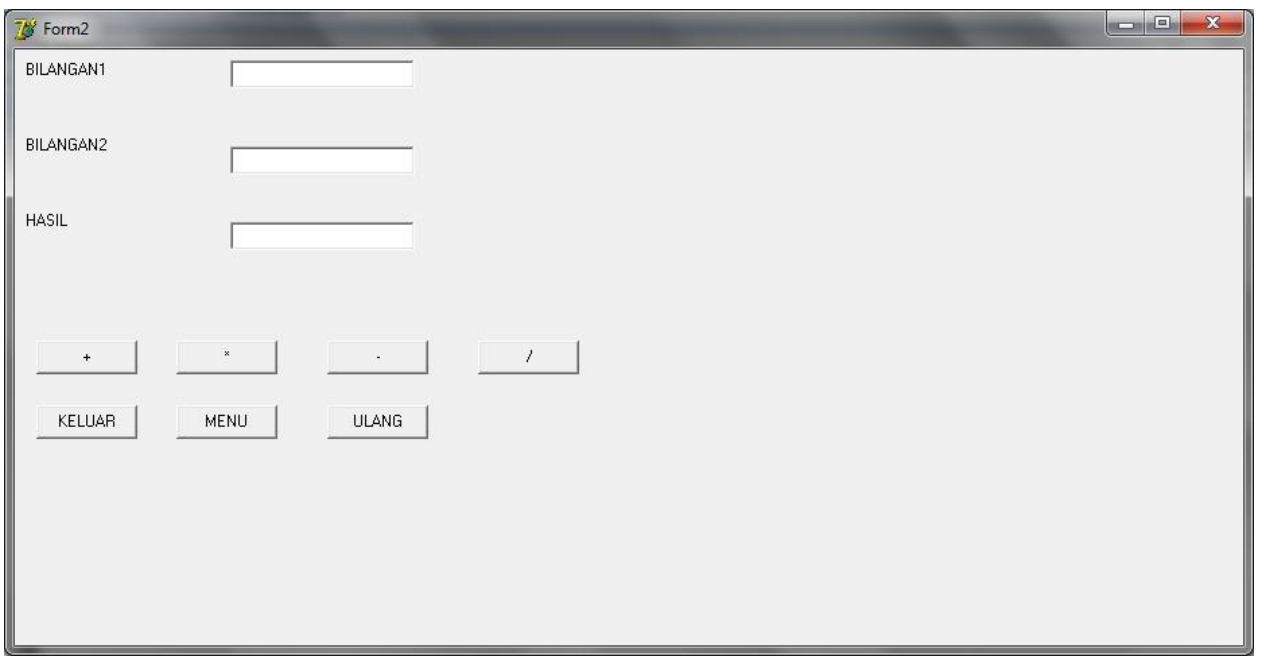




\section{DISKON}

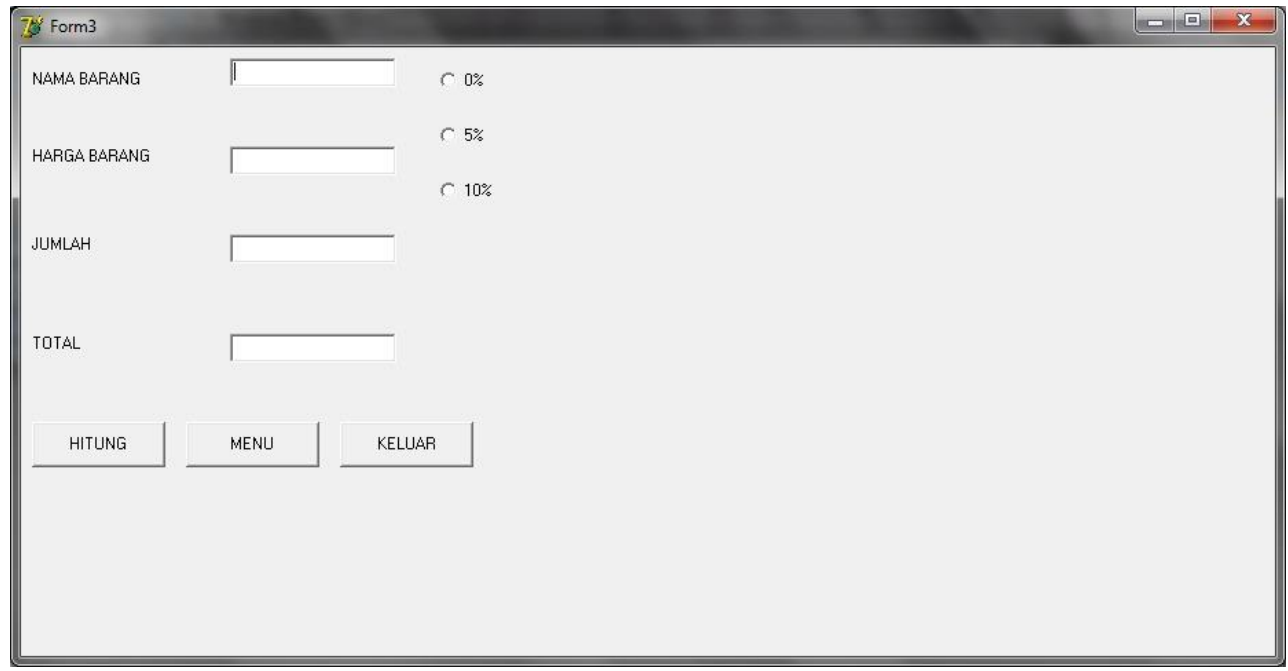

SEGITIGA

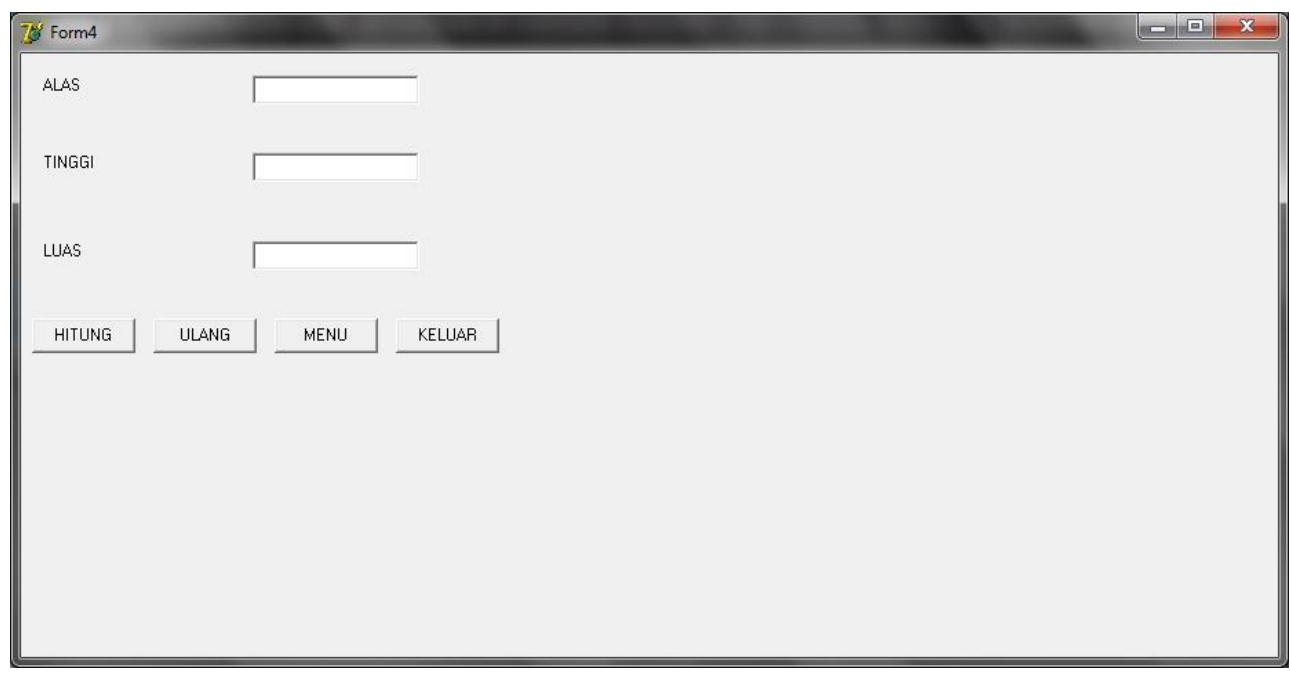

DATABASE

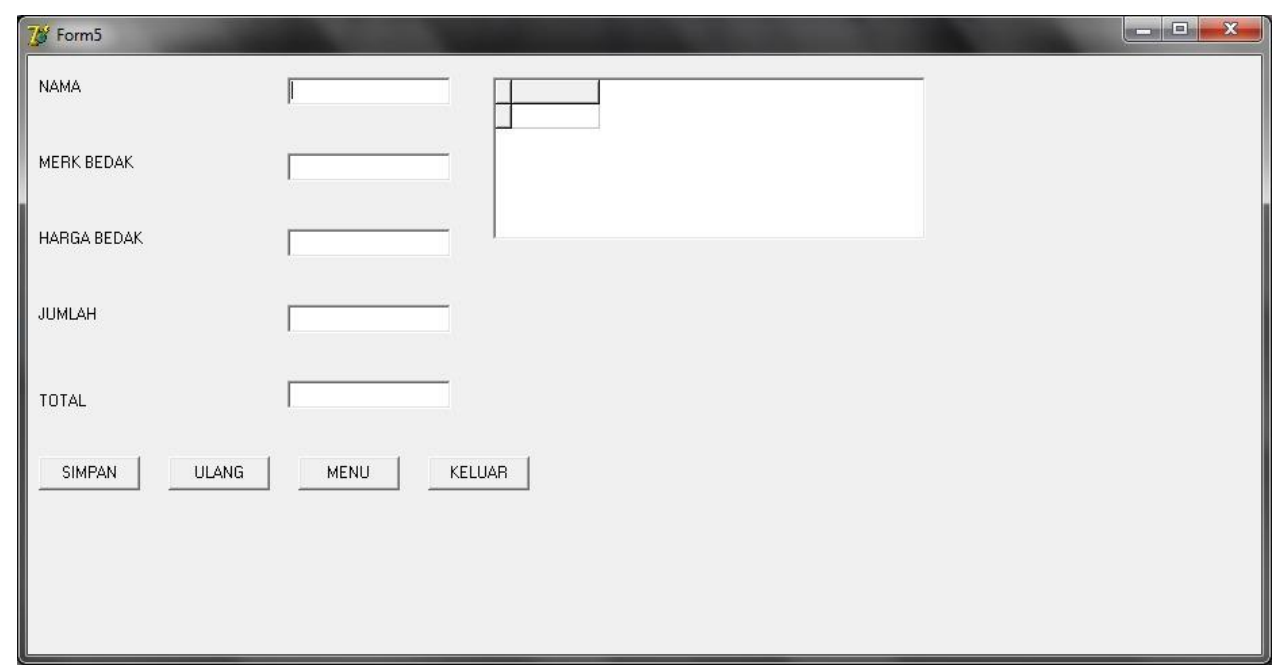




\section{B.PENJELASAN}

- Kalkulator

kalkulator merrupakan alat untuk menghitung dari sebuah penghitungan yang sederhana seperti penjumlahan,pengurangan,perkali an dan pembagian sampai dengan kalkulator dengan rumus tersulit

\section{- Diskon}

Adalah sebuah potongan harga yang disediakan pada setiap barang yang dijual oleh para penjual offline dan online agar produknya diminatiin oleh banyak pembeli, diskon merupakan potongan harga biasanya dipakai oleh pembisnis atau pedagang

\section{- Segitiga}

Segitiga adalah nama suatu bentuk yang dibuat dari tiga sisi yang berupa garis lurus dan tiga sudut aplikasi segitiga ini diharapkan untuk mempermudah kegiatan sehari hari jika diperlukan sesuatu hal untuk berpungsi sebaik mungkin

\section{- Database}

adalah merupakan aspek yang sangat penting dalam sistem informasi karna berfungsi sebagai gudang penyimpanan data yang akan diolah lebih lanjut

\section{Diskusi}

dari hasil diskusi saya dan teman teman saya lakukan aplikasi ini sangat bangus untuk mempermudah dalam menghitung tetapi dengan adanya aplikasi ini juga membuat mereka jadi pemalas.

\section{Refrensi}

[1]

S. Putra And O. M. Febriani, "Knowledge Management

Online Application In Pdam Lampung Province," In

Prosiding International Conference On Information Technology And Business (Icitb), 2018, Pp. 181-187.

[2]

A. S. Putra, O. M. Febriani, And

B. Bachry, "Implementasi

Genetic Fuzzy System Untuk

Mengidentifikasi Hasil Curian

Kendaraan Bermotor Di Polda

Lampung,"J. Sist. Inf. Dan Manaj. Basis

Data

, Vol. 1, No. 1, Pp. 21-30, 2018.

[3]

O. M. Febriani And A. S. Putra, "Sistem Informasi Monitoring Inventori Barang Pada Balai Riset Standardisasi Industri Bandar Lampung,"J. Inform. ,Vol. 13, No. 1, Pp. 90-98, 2014.

[4]

Putra, Arie

Setya. "2018 Artikel

Struktur Data, Audit Dan

Jaringan Komputer." (2018).

[5]

Putra, A. S. (2018, July 17).

Paperplain Fundamental Create

Application With Borland

Delphi 7.0 University Of Mitra

Indonesia. Retrieved From

Osf.Io/Pbrn9 
